\title{
The Isolation, Properties and Taxonomic Relevance of Lipid-soluble, Iron-binding Compounds (the Nocobactins) from Nocardia
}

\author{
By C. RATLEDGE AND P. V. PATEL \\ Department of Biochemistry, The University, Hull HU6 ${ }_{7} R X$
}

(Received 21 August 1975; revised 23 September 1975)

\begin{abstract}
SUMMARY
Representative strains of the genus Nocardia, when grown on iron-deficient media, produce intracellular lipid-soluble, iron-binding compounds known as nocobactins. However, strains representing the 'rhodochrous' taxon fail to form such compounds. The formation of the nocobactins is completely repressed in bacteria grown on iron-sufficient media. Procedures for purifying the nocobactins are described. From their various properties (u.v. and visible spectra of the ferriand desferri-materials, mobility upon thin-layer chromatography, and dissociation patterns in $\mathrm{HCl}$ ), they can be distinguished from the mycobactins (related compounds from mycobacteria) and divided into three main classes. The classes correspond to the three well-described species of the genus Nocardia: $N$. asteroides, $N$. brasiliensis and $N$. caviae. The correlation of the nocobactin data with previous results of conventional numerical taxonomy is high. Two strains of $N$. asteroides, however, did not produce nocobactins of the group type.
\end{abstract}

\section{INTRODUCTION}

Mycobacteria produce a series of lipid-soluble, iron-binding compounds, termed mycobactins, which show a variation in structure which offers a means of distinguishing the organisms at the species level (White \& Snow, 1968, 1969; Snow, 1970). Mycobactins are thought to occur throughout the genus Mycobacterium, with the exception of species such as Mycobacterium paratuberculosis (syn. johnei), strains of which depend upon them as growth factors (Morrison, 1965; Wheeler \& Hanks, 1965). Since the genera Mycobacterium, Nocardia and the allied rhodochrous taxon are difficult to separate (Goodfellow, I973; Goodfellow et al., 1974), representative strains of the major subgroups within the Nocardia and rhodochrous clusters (Goodfellow, 1971) have been examined to see whether they contain compounds similar to the mycobactins. Preliminary work (Patel \& Ratledge, 1973) which indicated the presence of such compounds in nocardiae has been extended to see if these materials have any taxonomic value at the subgeneric level, and whether they are sufficiently different from the mycobactins to provide a means of distinguishing the genera Nocardia and Mycobacterium. Simple physical techniques have been used to examine these compounds, for if they are to have any general value as chemotaxonomic markers then elaborate analytical procedures or complete structural analyses should be avoided if possible. The structure of one of these compounds, nocobactin NA, has been determined (Ratledge \& Snow, 1974). Since mycobactin production is greatly increased when the organisms are grown on iron-deficient medium (Ratledge \& Marshall, 1972), previously adopted techniques have been followed in our studies. 
Table I. Organisms examined for lipid-soluble, iron-binding compounds (listed according to the classification of Goodfellow, 1971)

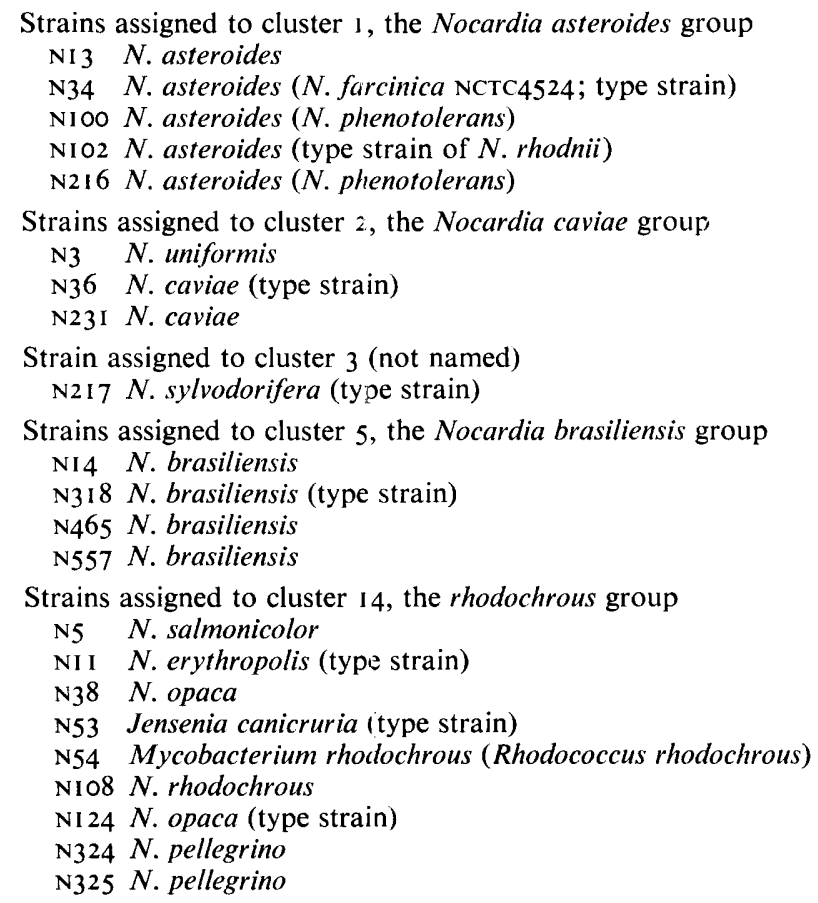

METHODS

Organisms. The organisms examined (see Table I) were obtained from Dr M. Goodfellow (University of Newcastle upon Tyne) as representative of the major taxonomic subgroups of Nocardia and the rhodochrous taxon.

Growth. All organisms were grown on medium at $\mathrm{pH} 6.8$ as previously described (Ratledge \& Hall, 197I), which was supplemented with $\mathrm{Zn}^{2+}(0.5 \mu \mathrm{g} / \mathrm{ml}), \mathrm{Mn}^{2+}(0 . \mathrm{I} \mu \mathrm{g} / \mathrm{ml})$ and $\mathrm{Mg}^{2+}$ $(0.04 \mathrm{mg} / \mathrm{ml})$. For iron-deficient growth $0.05 \mu \mathrm{g} \mathrm{Fe}{ }^{2+} / \mathrm{ml}$ was added, and for iron-sufficient growth $2.0 \mu \mathrm{g} \mathrm{Fe}^{2+} / \mathrm{ml}$. Bacteria were grown with shaking in $100 \mathrm{ml}$ of medium in $250 \mathrm{ml}$ Erlenmeyer flasks for 7 to 14 days at $30^{\circ} \mathrm{C}$, except for strains Nocardia brasiliensis N557, $N$. asteroides NI 3 and $N$. caviae $\mathrm{N} 36$ which were grown at $37^{\circ} \mathrm{C}$. Bacteria were harvested either by filtering through Whatman No. I paper or by centrifuging, and then washed with distilled water.

Extraction of nocobactins and their purification. Freshly harvested, still-moist bacteria were held in ethanol at room temperature for not less than $18 \mathrm{~h}$, preferably for 40 to $48 \mathrm{~h}$, and removed by filtering through sintered glass crucibles (No. 2 porosity) or Whatman No. I filter paper. Either of two procedures was then followed for the purification of the nocobactins in the ethanolic filtrates:

Procedure 1 (for ferri-nocobactins). The material was immediately converted to the ferri form by adding $\mathrm{FeCl}_{3}$, and the procedure given by Ratledge \& Snow (1974) followed. Chloroform-acetone $(\mathrm{I}: \mathrm{s}, \mathrm{v} / \mathrm{v})$ did not always elute the material adsorbed to the alumina, and in such cases methanol-5 $\mathrm{M}-\mathrm{HCl}(20: \mathrm{I}, \mathrm{v} / \mathrm{v})$ was used. The nocobactin was further purified as given below.

Procedure 2 (for desferri-nocobactins). The ethanolic extract, without addition of 
$\mathrm{FeCl}_{3}$, was mixed with an equal volume of chloroform, and saturated $\mathrm{NaCl}$ solution added until two layers formed. The lower chloroform layer was run off, dried over anhydrous $\mathrm{MgSO}_{4}$ and evaporated. The creamish-white residue was washed with diethyl ether $(2 \times 15 \mathrm{ml})$ and once with $10 \mathrm{ml}$ petroleum spirit (b.p. 40 to $\left.60{ }^{\circ} \mathrm{C}\right)$. The residue, essentially metal-free nocobactin, was then converted into the ferri form by adding $\mathrm{FeCl}_{3}$ in ethanol and purified as given below.

In each case the final purification step was chromatography of the ferri-nocobactin on a $400 \times 35 \mathrm{~mm}$ column of alumina (Brockmann grade, neutral). After washing with $500 \mathrm{ml}$ cyclohexane, the nocobactin was eluted by either: (i) cyclohexane-t-butanol $(9: \mathrm{I}, \mathrm{v} / \mathrm{v})$ for nocobactins from $N$. uniformis, $N$. asteroides $\mathrm{N} 13, \mathrm{~N} 34$ and NIO2, and $N$. sylvodorifera; (ii) chloroform only for nocobactins from $N$. caviae $\mathrm{N} 36$ and N23I, N. asteroides $\mathrm{NIOO}$ and N2I6, and $N$. brasiliensis NI4; or (iii) cyclohexane-ethyl acetate $(4: \mathrm{I}, \mathrm{V} / \mathrm{v})$ followed by methanol-5 $\mathrm{M}-\mathrm{HCl}(20: \mathrm{I}, \mathrm{v} / \mathrm{v})$ for $N$. brasiliensis $\mathrm{N} 318$ and $\mathrm{N} 557$. (The nocobactin from $N$. brasiliensis $\mathrm{N} 465$ was not purified beyond the initial procedure.)

Eluates from the column were concentrated and re-chromatographed under similar conditions, this usually being sufficient to raise the $E_{1 \mathrm{~cm}}^{1^{\circ} \mathrm{cm}}$ value at 450 or $460 \mathrm{~nm}$ to its maximum.

Determination of the nocobactin content. The method of determination was similar to that described by White \& Snow ( 1969) for assessing the amount of mycobactins in mycobacteria. Essentially, the extinction value of the unpurified ferri-nocobactin was corrected by mixing a sample held in methanol with an equal volume of $6 \mathrm{M}-\mathrm{HCl}$ and re-reading at the same wavelength.

Bacterial dry weights were determined after ethanolic extraction by holding the residue under vacuum at $50{ }^{\circ} \mathrm{C}$ until a constant weight had been attained.

Production of metal-free nocobactins. Ferri-nocobactin, purified to a constant $E_{1 \text { cin }}^{1 \text {," was }}$ dissociated in $6 \mathrm{M}-\mathrm{HCl}$ in methanol and the nocobactin extracted with an equal volume of chloroform. The chloroform layer was washed until free of acid, using all-glass doubledistilled water, then evaporated to give a cream powder.

Ultraviolet and visible spectroscopy. The spectra of ferri- and desferri-nocobactins were determined in methanol using either a Unicam SP 800 recording spectrophotometer or a Cary I4 UV spectrophotometer. $E_{1 \mathrm{~m}}^{1 \%}$ values were determined with the latter instrument.

Thin-layer chromatography of ferri-nocobactins was carried out on $0.25 \mathrm{~mm}$-thick layers of silica gel $\mathrm{G}$ (Anachem Ltd, Luton) with either (I) petroleum spirit (b.p. 40 to $60{ }^{\circ} \mathrm{C}$ ) - $n$-butanol-ethyl acetate $(2: 3: 3$, by vol.); (II) isopropanol alone; or (III) benzene-ethyl acetate $(\mathrm{I}: \mathrm{I}, \mathrm{V} / \mathrm{v})$. As streaking readily occurred in the latter system, very small spots (about $\mathrm{I}$ to $2 \mathrm{~mm}$ diam) had to be applied for satisfactory results.

Mercuric acetate adducts. Methanolic solutions of ferri- and desferri-nocobactins of $N$. caviae and $N$. brasiliensis were amended with $5 \%(\mathrm{w} / \mathrm{v})$ excess mercuric acetate and kept either at room temperature for $24 \mathrm{~h}$ (Jantzen \& Andreas, I96I) or refluxed at $50{ }^{\circ} \mathrm{C}$ for I $\mathrm{h}$ (White, I966). An equal volume of chloroform was added with a sufficient amount of water io form two layers. The chloroform layer was run off, repeatedly washed with water to remove excess mercuric acetate, and dried with anhydrous $\mathrm{MgSO}_{4}$. Nocobactins were then subjected to t.l.c. using solvent system I.

Argentation chromatography. Thin-layer chromatography of ferri- and desferri-nocobactins was also carried out on silica gel $\mathrm{G}$ containing $5 \%(\mathrm{w} / \mathrm{v})$ silver nitrate using solvent system (I). Desferri compounds were detected on development either by their fluorescence under u.v. irradiation or by $2 \%(\mathrm{w} / \mathrm{v}) \mathrm{FeCl}_{3}$ reagent in acetone.

Dissociation of ferri-nocobactins. Dissociation of ferri-nocobactins was achieved by 
adding $\mathrm{I} \mathrm{ml}$ of $\mathrm{HCl}$ of various molarities to $3 \mathrm{ml}$ of methanolic solutions of each ferrinocobactin; $E_{450}$ values were then determined.

Examination of triplet of nocobactins from N. uniformis. Thin-layer chromatography of the ferri-nocobactins from $N$. uniformis in all solvent systems used showed three distinct compounds (see Table 5). Preparative t.l.c. was performed on I mm-thick silica gel G plates $(400 \times 200 \mathrm{~mm})$ and after development each compound was scraped off and eluted with chloroform-methanol $(2: \mathrm{I}, \mathrm{v} / \mathrm{v})$. Each component was checked for purity by re-running a sample on an analytical plate with the same solvent system; chromatograms were examined under u.v. light and also by charring with chromic acid/sulphuric acid reagent at $200{ }^{\circ} \mathrm{C}$ to detect any organic impurities (Kirchner, I967). The u.v. spectrum of each component, in the ferri- and desferri-forms, was then determined. Each was then hydrolysed by refluxing with $6 \mathrm{M}-\mathrm{HCl}$ for $6 \mathrm{~h}$. The solutions were extracted three times with equal volumes of diethyl ether, and the extracts dried over $\mathrm{MgSO}_{4}$ and methylated with diazomethane. The methyl esters were examined by g.l.c. using a column ( $1.5 \mathrm{~m} \times 6 \mathrm{~mm})$ of $10 \%(\mathrm{w} / \mathrm{v})$ diethyl glycol succinate on acid-washed celite and running isothermally at either I25 or $175{ }^{\circ} \mathrm{C}$ with $\mathrm{N}_{2}$ as carrier gas.

Mycobactins. Mycobactins Av, S and T were prepared from Mycobacterium avium, $M$. smegmatis and $M$. bovis var. BCG, respectively. Samples of mycobactin $\mathrm{P}$ (from $M$. phlei), mycobactin $\mathrm{M}$ (from $M$. marinum) and mycobactins $\mathrm{F}+\mathrm{H}$ (from $M$. fortuitum) were kindly supplied by Professor G. A. Snow (ICI Ltd, Macclesfield, Cheshire).

\section{RESULTS}

\section{Isolation of nocobactins}

All the nocardiae examined produced a lipid-soluble, iron-binding compound. These nocobactins were extracted by ethanol from freshly harvested cells with varying degrees of ease; $N$. caviae (N36) and $N$. asteroides NIO2 took the longest, with about $35 \mathrm{~h}$ needed for complete removal of their nocobactins. The nocobactins resembled the mycobactins in their general properties. The yields of nocobactins (Table 2) varied according to the strains examined, but were similar to those recorded by Snow (1970) for the mycobactins. All bacteria when grown in shake-cultures with a sufficiency of iron $(2 \mu \mathrm{g} \mathrm{Fe} / \mathrm{ml})$ contained only traces of nocobactin. Presumably the amount formed approximates to the quantity of mycobactin synthesized under similar conditions, i.e. about $50 \mu \mathrm{g} / \mathrm{g}$ dry wt (L. P. Macham, unpublished work). The production of the nocobactins from $N$. asteroides NI $3, N$. brasiliensis N557 and $N$. caviae $\mathrm{N} 36$ at different concentrations of iron is given in Fig. I.

No lipid-soluble, iron-binding compound was extracted with ethanol, or with chloroformmethanol $(2: \mathrm{I}, \mathrm{v} / \mathrm{v})$, from the nine rhodochrous organisms even upon prolonged contact with these solvents.

\section{Purification of nocobactins}

The modified methods of purifying the nocobactins decreased the total number of steps which Snow (1965) used to purify the mycobactins. The losses sustained during purification (see Table 2) were much less than those experienced by Snow (1965), who recovered only about $\mathrm{I} \%$ of the original material in some cases. With strains of $N$. brasiliensis, purification was greatly improved by using the desferri-materials, as the ferri-materials adsorbed almost irreversibly to the alumina.

When finally purified, all nocobactins except that from $N$. uniformis moved as single spots or a close doublet of spots upon t.l.c. (see below) and had $E_{1 \mathrm{~cm}}^{1 \%}$ values at 450 or $460 \mathrm{~nm}$ 
Table 2. Yields and recoveries of nocobactins during purification

\begin{tabular}{|c|c|c|c|c|c|c|c|c|c|}
\hline \multirow[b]{3}{*}{ Organism } & \multirow{3}{*}{$\begin{array}{c}\text { Nocobactin } \\
\text { produced } \\
\text { (percentage } \\
\text { of } \\
\text { bacterial } \\
\text { dry wt) }\end{array}$} & \multicolumn{4}{|c|}{$\begin{array}{l}\text { Purification procedure I } \\
\text { (as ferri-nocobactin)* }^{*}\end{array}$} & \multicolumn{4}{|c|}{$\begin{array}{l}\text { Purification procedure } 2 \\
\text { (as desferri-nocobactin)* }^{*}\end{array}$} \\
\hline & & \multirow[b]{2}{*}{$E_{450 \mathrm{~nm}}^{110}$} & \multirow[b]{2}{*}{$\begin{array}{l}\text { Yield } \\
(\%)\end{array}$} & \multicolumn{2}{|c|}{ Stage II } & \multicolumn{2}{|c|}{ Stage I } & \multicolumn{2}{|c|}{ Stage II } \\
\hline & & & & $E_{450 \mathrm{~nm}}^{100}$ & $\begin{array}{c}\text { Overall } \\
\text { yield } \\
(\%)\end{array}$ & $E_{450 \mathrm{~nm}}^{106}$ & $\begin{array}{c}\text { Overall } \\
\text { yield } \\
(\%)\end{array}$ & $E_{450 \mathrm{~nm}}^{100}$ & $\begin{array}{c}\text { Overall } \\
\text { yield } \\
\left(\begin{array}{c}0 \\
10\end{array}\right)\end{array}$ \\
\hline Nocardia asteroides $\mathrm{NI} 3$ & $3 \quad 10 \cdot 2$ & $3 I \cdot 8$ & $60 \cdot 8$ & $44 \cdot 2$ & $20 \cdot 3$ & $37 \cdot 9$ & $41 \cdot 5$ & $43 \cdot 8$ & $17 \cdot 7$ \\
\hline N. asteroides N34 & $7 \cdot 2$ & $31 \cdot 8$ & $67 \cdot 5$ & $44 \cdot 0$ & $19 \cdot 2$ & $\ldots$ & - & - & $\therefore$ \\
\hline N. asteroides $\mathrm{N} 102$ & $3 \cdot 1$ & - & $\ldots$ & - & - & $38 \cdot 3$ & $59 \cdot 9$ & $43 \cdot 9$ & $12 \cdot 3$ \\
\hline N. asteroides $\mathrm{N} 216$ & 10.9 & - & --- & - & - & $37 \cdot 4$ & $62 \cdot 5$ & $43 \cdot 6$ & $19 \cdot 5$ \\
\hline N. uniformis $\mathrm{N} 3$ & $5 \cdot 9$ & - & $\cdots$ & - & 一 & $38 \cdot 4$ & $8 \mathbf{I} \cdot \mathbf{2}$ & $44 \cdot 2$ & $28 \cdot 7$ \\
\hline N. caviae $\mathrm{N} 36$ & $8 \cdot 9$ & $30 \cdot 5$ & $64 \cdot 4$ & $43 \cdot 8$ & $20 \cdot 9$ & $37 \cdot 0$ & $53 \cdot 3$ & $43 \cdot 8$ & $16 \cdot 7$ \\
\hline N. caviae N23I & $4 \cdot 9$ & $32 \cdot 7$ & $59 \cdot 3$ & $44 \cdot I$ & $12 \cdot 8$ & $36 \cdot 7$ & $57 \cdot 8$ & $43 \cdot 8$ & $13 \cdot 8$ \\
\hline N. sylvodorifera $\mathrm{N} 2 \mathrm{I} 7$ & $5 \cdot 8$ & - & -- & $\cdots$ & - & - & - & - & 一 \\
\hline N. phenotolerans NIOO & $8 \cdot 7$ & 一 & -- & $\longrightarrow$ & - & $38 \cdot 2$ & $54 \cdot 5$ & $43 \cdot 4$ & $14 \cdot 2$ \\
\hline N. brasiliensis NI 4 & $7 \cdot 4$ & - & -- & - & - & $37 \cdot 8$ & $54 \cdot \mathrm{I}$ & $43 \cdot 6$ & $15 \cdot 9$ \\
\hline N. brasiliensis N3 I 8 & $4 \cdot 8$ & $31 \cdot 5$ & $32 \cdot 7$ & $45^{\circ} 0$ & $8 \cdot 2$ & $38 \cdot 0$ & $6 I \cdot 5$ & $45 \cdot 2$ & $14 \cdot 6$ \\
\hline N. brasiliensis $\mathrm{N} 465$ & $4 \cdot 2$ & 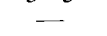 & - & - & - & $\ldots$ & - & - & - \\
\hline N. brasiliensis N557 & $9 \cdot 7$ & $29 \cdot 1$ & $25 \cdot 0$ & $43 \cdot 8$ & $1 \cdot 8$ & $37 \cdot 6$ & $58 \cdot 6$ & $44 \cdot I$ & $18 \cdot 6$ \\
\hline
\end{tabular}

* See Methods for full details. Stage I, before chromatography on alumina column; Stage II, after chromatography on alumina column.

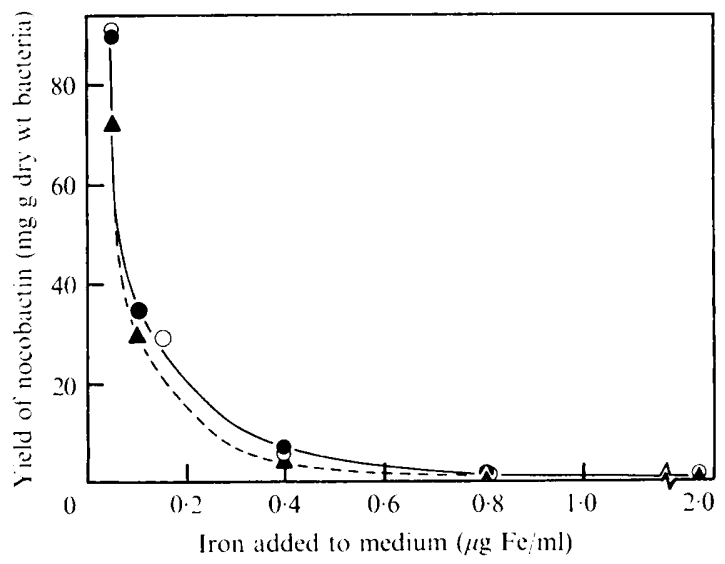

Fig. I. Relationship of nocobactin formation to the concentration of iron in growth media. Nocobactins from $N$. asteroides NI3 (O), N. brasiliensis N557 (O) and $N$. caviae N36 (A) after 7 days' growth with continuous shaking.

of about 42 to 43 , indicating a purity of at least $98 \%$ assuming a maximum $E_{1 \mathrm{~cm}}^{10 \%}$ value of between 43 and 45 (see Snow, 1970; Ratledge \& Snow, 1974).

\section{Properties and characterization of nocobactins}

Although the structure of nocobactin NA is distinct from that of any mycobactin (Ratledge \& Snow, 1974), a simple technique to distinguish the nocobactins from the mycobactins is needed for taxonomic purposes. The remainder of this paper is therefore 
Table 3. Characteristics of the spectra of purified nocobactins

$\begin{array}{ccc} & \text { Extinction } & \\ & \text { coefficients of } & \\ \text { ferri-nocobactins } & \\ \left(E_{1 \%}^{\mathbf{1} \%} \text { at } \lambda_{\max }\right. & \text { U.v. spectrum of desferri-nocobactins } \\ \text { Source of nocobactin } & \text { in }\left(\lambda_{\max }, \mathrm{nm}\right)\end{array}$

Group I

Nocardia asteroides NI $3 \quad 44^{\cdot 2}$

$N$. asteroides $\mathrm{N} 34$

$N$. asteroides $\mathrm{N} 102$

N. uniformis $\mathrm{N} 3$

$254,260,266,272,278,308 \cdot 5,319$

$256,26 \mathrm{I}, 267,272 \cdot 5,279,309,318 \cdot 5$

$252,257 \cdot 5,263,269,275,307,320$

Group 2

N. caviae $\mathrm{N} 36$

$N$. caviae $\mathrm{N} 23 \mathrm{I}$

$N$. asteroides $\mathrm{N} 2 \mathrm{I} 6$

$N$. phenotolerans NIOO

$N$. brasiliensis $\mathrm{N} 557$

N. brasiliensis N3 8

$N$. brasiliensis NI4

$43 \cdot 8$

$44 \cdot 1$

$43 \cdot 6$

$43 \cdot 4$

$44 \cdot 1$

$45^{\circ} \mathrm{O}$

$43 \cdot 6$

$250,255,261,267,274,305,319$

(Mycobactin from Mycobacterium smegmatis)

$(42 \cdot 8)$
$242,249,259 \cdot 5,303$
$242,249,258 \cdot 5,303 \cdot 5$
$239.5,248,259,305$
$24 \mathrm{I} \cdot 5,248 \cdot 5,259,303 \cdot 5$
$24 \mathrm{I} \cdot 5,248,258 \cdot 5,303 \cdot 5$
$240 \cdot 5,247 \cdot 5,258,303 \cdot 5$
$240,247,259 \cdot 5,305$

$(240,249,260,305)$
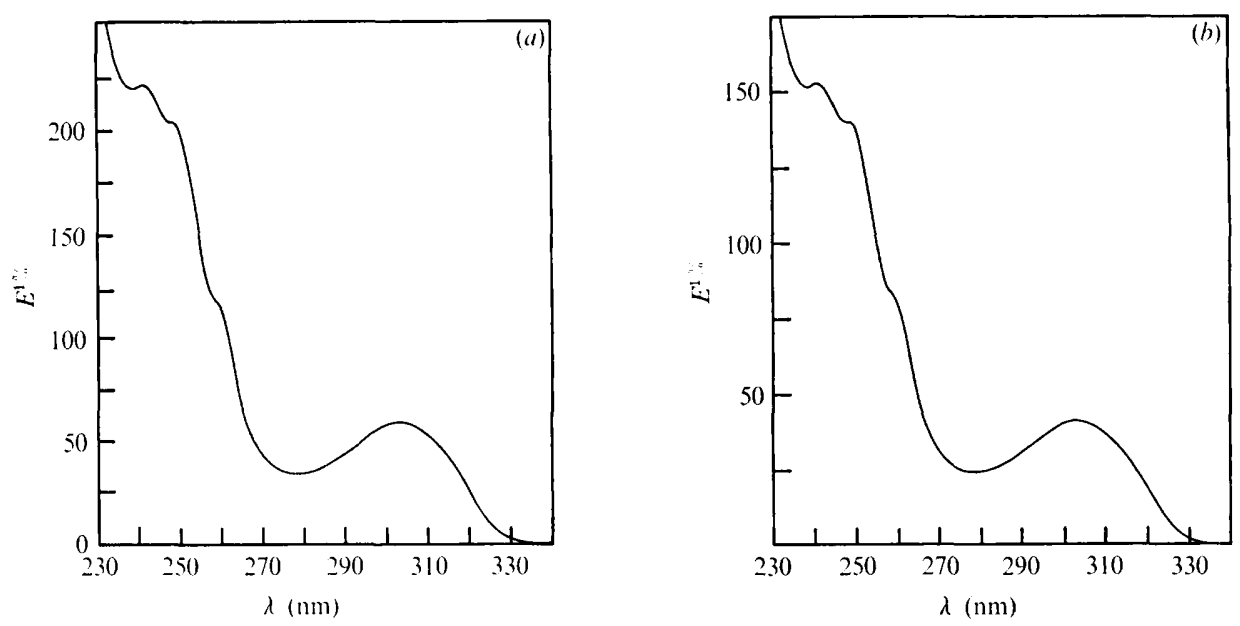

Fig. 2. Spectra of desferri-nocobactins from N. caviae N23I (a) and N. brasiliensis N557 (b). Both_determined in methanolic solution.

devoted to an examination of this objective rather than to a determination of structure for each compound.

Ultraviolet spectroscopy. Nocobactins fell into two groups according to their u.v. spectra: (i) those conforming to the multi-peak type of spectrum shown by $N$. asteroides $\mathrm{N} 34$ (Ratledge \& Snow, 1974), and (ii) those conforming to a mycobactin type of spectrum (see Table 3, and Fig. 2). The nocobactins of N. asteroides NIO2 and N. uniformis showed hypsochromic shifts of about 4 to $5 \mathrm{~nm}$ due to the absence of a methyl group in the oxazole ring of the nocobactin NA molecule (for structure, see Ratledge \& Snow, 1974).

The nocobactins from $N$. brasiliensis and $N$. caviae could not be distinguished from each other, or from the mycobactins, by their u.v. spectra (see Fig. 2); however, the corresponding 

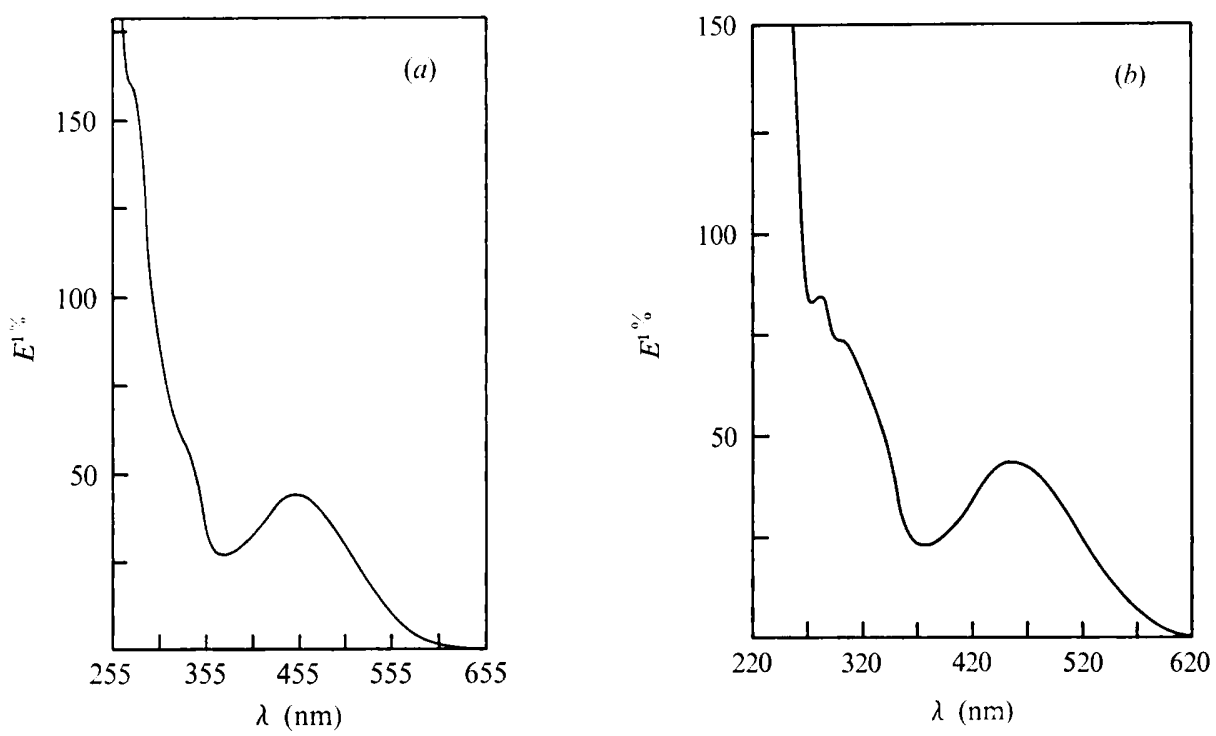

Fig. 3. Spectra of ferri-nocobactins from N. caviae N23I (a) and N. brasiliensis N3I8 (b). Both determined in methanolic solution.

Table 4. Characteristics of the spectra in the 250 to $310 \mathrm{~nm}$ region of ferri-nocobactins from nocardiae of group 2

All compounds also showed a shoulder at 330 to $335 \mathrm{~nm}$, besides their principal peak in the visible region at 450 to $460 \mathrm{~nm}$.

\begin{tabular}{|c|c|}
\hline Source of nocobactin & $\lambda_{\max }$ or shoulders \\
\hline Nocardia caviae N36 & 278 (shoulder) \\
\hline N. caviae $\mathrm{N} 23 \mathrm{I}$ & 276 (shoulder) \\
\hline N. asteroides $\mathrm{N} 2 \mathrm{I} 6$ & 284,309 (shoulder) \\
\hline N. phenotolerans N100 & 278,309 (shoulder) \\
\hline N. brasiliensis $\mathrm{N} 557$ & 283,310 \\
\hline N. brasiliensis N3I 8 & 283,310 \\
\hline N. brasiliensis N14 & 310 \\
\hline N. brasiliensis N465 & 283,310 \\
\hline Source of mycobactin & \\
\hline Mycobacterium smegmatis & 278 (shoulder) \\
\hline M. bovis var. $\mathrm{BCG}$ & 250 \\
\hline M. marinum & 278, 309 (shoulder) \\
\hline
\end{tabular}

ferri-nocobactins did show distinct differences (Fig. 3; Table 4). The ferri-nocobactins of the brasiliensis type, except for that from N. brasiliensis NI4, gave a doublet of peaks in the 280 to $310 \mathrm{~nm}$ region (that from $N$. brasiliensis NI 4 gave a single peak at $310 \mathrm{~nm}$ ). Ferrinocobactins of the caviae type gave only a single peak at 276 or $278 \mathrm{~nm}$, whereas those from $N$. asteroides N2I 6 and NIOO, tentatively classified outside the asteroides group, gave a doublet of peaks in the region close to those shown by ferri-nocobactins of the brasiliensis type (ferri-nocobactins of the asteroides type, not listed in Table 3, gave peaks at $269 \mathrm{~nm}$ and $324 \mathrm{~nm}$; Ratledge \& Snow, 1974). Ferri-mycobactins S, T and M could be distinguished from each other by their u.v. spectral characteristics (Table 4); only mycobactin $S$ was similar to one of the nocobactins, i.e. to that from $N$. phenotolerans. 
Table 5. Thin-layer chromatography of ferri-nocobactins and some ferri-mycobactins

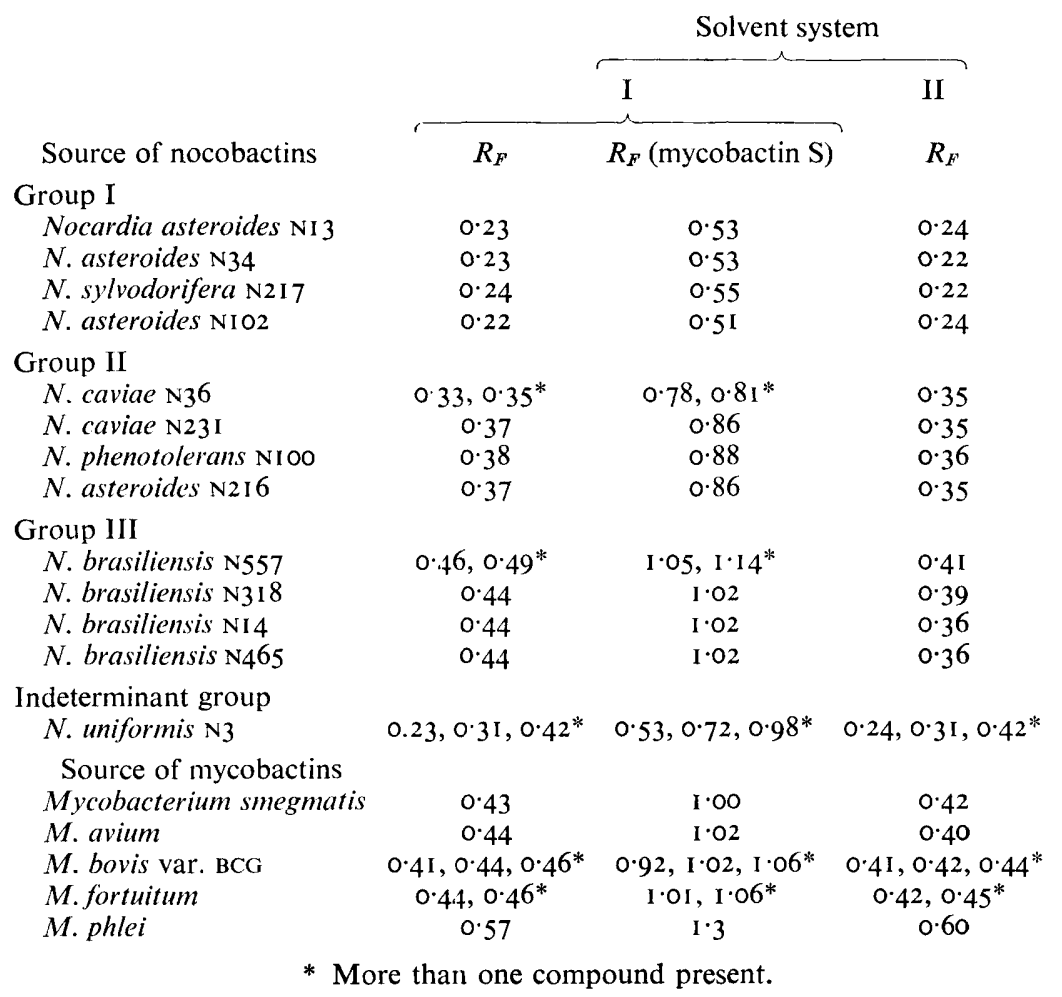

Chromatography. Thin-layer chromatography of the ferri-nocobactins in solvent system I (Table 5) resolved them into three groups according to $R_{F}$ values: (i) those of the nocobactin NA type which again included the strain of $N$. sylvodorifera $(N$. uniformis $\mathrm{N} 3$ was anomalous in giving three distinct spots, one of which had the $R_{F}$ value characteristic of this group); (ii) those derived from $N$. caviae, and (iii) those from $N$. brasiliensis. The nocobactins from $N$. asteroides N10O and N2I6 both fell within the caviae group. The nocobactins from $N$. brasiliensis had similar $R_{k}$ values to the mycobactins from various mycobacteria and could not be satisfactorily distinguished from them (Table 5 ). In solvent system II, however, most nocobactins of the brasiliensis type could be separated from the mycobactins; $N$. brasiliensis $\mathrm{N} 557$ had the same $R_{F}$ value as that from $M$. bovis var. BCG.

Nocobactins of the brasiliensis type could be clearly separated from the mycobactins using the solvent system benzene-ethyl acetate $(\mathrm{I}: \mathrm{I}, \mathrm{v} / \mathrm{v})$, though this system did not resolve the mycobactins or the other nocobactins. Using a double development of this solvent system, all nocobactins from the $N$. brasiliensis strains had $R_{F}$ values of 0.14 to 0.15 whereas all mycobactins and other nocobactins had $R_{F}$ values of 0.05 .

Attempts to distinguish the various nocobactins by forming mercuric acetate adducts, or by argentation chromatography, were unsuccessful. Presumably $>\mathrm{C}=\mathrm{C}<$ groups within the molecules must be inaccessible for bonding to heavy metals.

Dissociation. The dissociation curves for each nocobactin were determined (Fig. 4). The nocobactins from all four strains of $N$. brasiliensis were insoluble in $75 \%$ methanol and could therefore not be examined. 

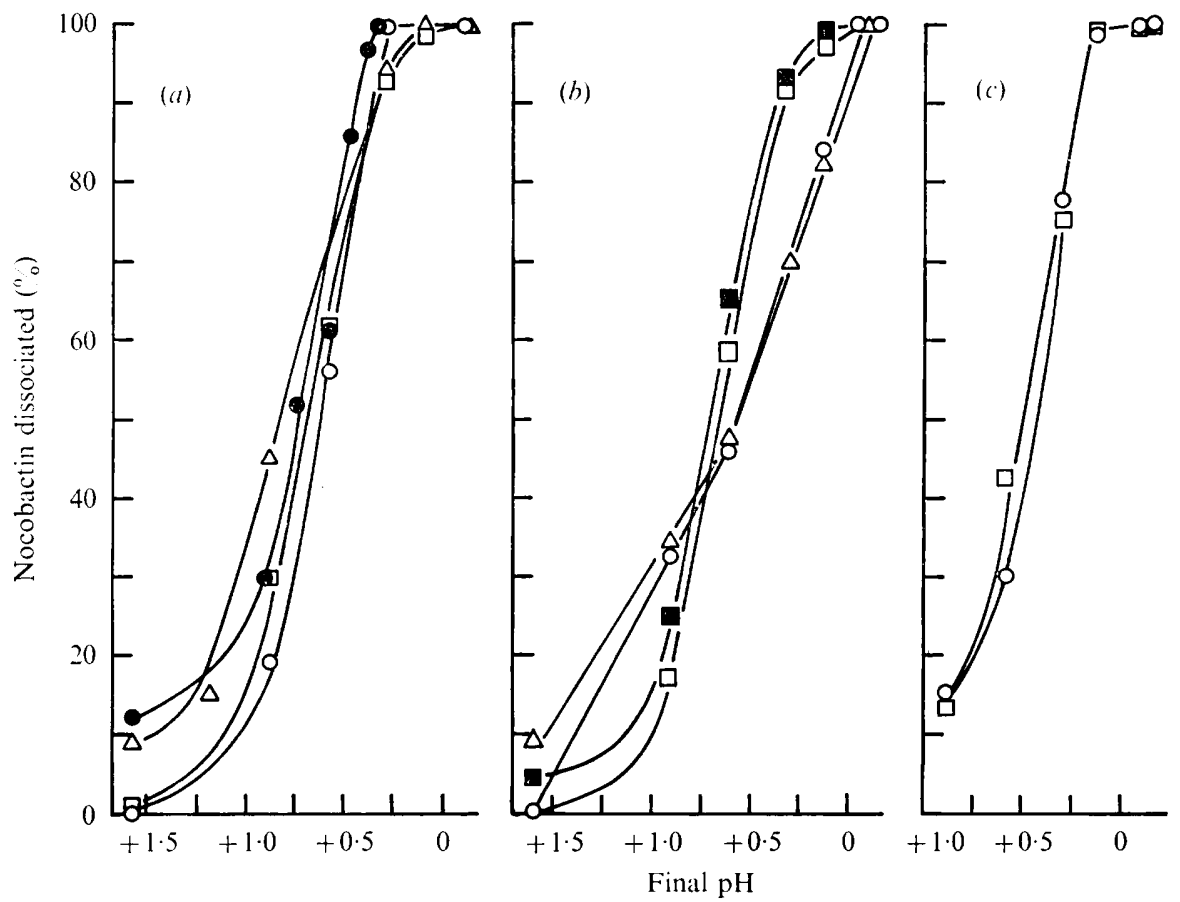

Fig. 4. Dissociations of nocobactins and two mycobactins in HCI. (a) Nocobactins from $N$. asteroides $\mathrm{N1} 3(\bigcirc), N$. asteroides $\mathrm{N} 34(\square), N$. sylvodorifera $\mathrm{N} 2 \mathrm{I} 7(\bullet)$ and $N$. uniformis $\mathrm{N} 3(\triangle)$;

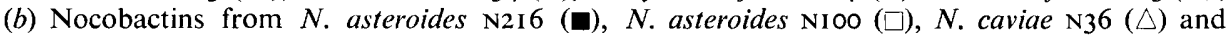
$N$. caviae N23I (O); (c) Mycobactins from M. smegmatis $(\bigcirc)$ and M. avium $(\square)$.

Nocobactins from $N$. asteroides $\mathrm{NI} 3, \mathrm{~N} 34$ and NI02, and $N$. uniformis had $50 \%$ dissociation values (at $\mathrm{pH}$ values $0.70,0.64,0.76$ and 0.84 , respectively) which were distinct from those of the two nocobactins from $N$. caviae. The latter were $50 \%$ dissociated at $\mathrm{pH} 0.54$ but were further distinguished by biphasic dissociation curves (see Fig. 4). The nocobactins from $N$. asteroides NIOO and N2I 6 did not show this characteristic and were $50 \%$ dissociated at $\mathrm{pH}$ values 0.64 and 0.69 , respectively, results more in keeping with those from the $N$. asteroides group.

Mycobactins from $M$. smegmatis and $M$. avium had identical dissociation curves, being $50 \%$ dissociated at $\mathrm{pH} 0.54$.

\section{Examination of the three nocobactins from $N$. uniformis}

Thin-layer chromatography of the purified nocobactins from $N$. uniformis showed three components in approximately equal proportions. The dissociation curve of the combined material (Fig. 4) did not suggest that these components had different dissociation values. The u.v. spectra of each component when isolated by preparative t.l.c. were identical and therefore were each the same as the spectrum given by the combined material (Table 3 ). Degradation of each component followed by g.l.c. analysis of the ensuing fatty acids (as methyl esters) showed that each one contained between eleven and thirteen fatty acids ranging from $\mathrm{C}_{8}$ to $\mathrm{C}_{18}$, albeit in different proportions. The differences in t.l.c. mobilities of the three compounds are, therefore, not due to differences in the chain length of the acyl 
substituents as each would then have given a similar multiplicity of spots. The three constituents of this nocobactin must therefore differ in some other substituent.

\section{Classification system}

The following criteria are suggested for classifying nocobactins, using the nomenclature of Ratledge \& Snow (1974), without determining their chemical structure:

Nocobactins NA (from $N$. asteroides). These show a distinctive multipeak u.v. spectrum which is due to the occurrence of an oxazole ring in place of the oxazoline ring found in other nocobactins and mycobactins.

Nocobactins NB (from $N$, brasiliensis). These appear closest in properties to the mycobactins; they do not, however, dissolve in $75 \%$ methanol, and can be resolved from the mycobactins and other nocobactins by t.l.c. using benzene-ethyl acetate $(\mathrm{I}: \mathrm{I}, \mathrm{v} / \mathrm{v})$. In the ferri-form they may be resolved from most mycobactins and nocobactin NC by careful spectroscopy in the 250 to $310 \mathrm{~nm}$ region.

Nocobactins NC (from N. caviae). These have mobilities in t.l.c. intermediate to those of nocobactins NA and NB, and may be further distinguished from nocobactin NB by the appearance of only a single peak in the $290 \mathrm{~nm}$ region of the u.v. spectrum of the ferrinocobactin.

\section{DISCUSSION}

The occurrence of lipid-soluble, iron-binding compounds in nocardiae and mycobacteria is further evidence of a similarity between these organisms. The failure to find similar compounds in strains of the rhodochrous taxon distinguishes it from the genera Nocardia and Mycobacterium; this result is in good agreement with the findings of Goodfellow et al. (1974). Whether organisms of the rhodochrous taxon have lost the ability, or need, to produce such compounds or have never possessed them is unknown but it is clearly important to know how these organisms transport iron into the cell. Rhodochrous strains have a similar wall structure to mycobacteria and nocardiae (Williams et al., 1976) and therefore the problems of iron acquisition might be expected to be similar for strains in all three taxa. The production of lipid-soluble, iron-binding compounds in mycobacteria and nocardiae is probably due to the thick lipid-rich bacterial envelope preventing the ready uptake of iron unless it was chelated to a lipid-soluble molecule (Ratledge \& Marshall, I972). Although this view may be correct, an alternative method of iron uptake has clearly been achieved by members of the rhodochrous taxon.

The occurrence of three readily distinguishable types of nocobactin has been established and these correspond to the three main clusters of the genus Nocardia delineated by Goodfellow (197I), i.e. $N$. asteroides, $N$. brasiliensis and $N$. caviae. Data from the dissociation of the nocobactins do not seem particularly useful in classifying the nocobactins although they have indicated that there may be two types of nocobactin NC, that is one corresponding to $N$. caviae per se and the other to those from $N$. phenotolerans and $N$. asteroides N2 I6. The biphasic dissociation curves for the former type of nocobactin must be due to differences in the ease at which protonation of the molecule occurs at different sites.

The nocobactins from $N$. uniformis and $N$. sylvodorifera each corresponded to nocobactin NA and on this basis these strains should be classified as $N$. asteroides. Nocardia uniformis, though grouped into the $N$. caviae cluster by conventional numerical taxonomic methods (Goodfellow, I97I), did show high similarities with several strains of $N$. asteroides. Nocardia sylvodorifera shared an 85 to $90 \%$ similarity to several strains in the $N$. asteroides cluster 
including $N$. asteroides NI3 which was examined here. Other organisms besides $N$. sylvodorifera which Goodfellow (197I) assigned to cluster 3, a rather diffuse taxon, might therefore be examined to see if they too produce nocobactins of the NA type. Similarly, other strains of $N$. uniformis and closely related organisms warrant further investigation.

Our finding that the nocobactins of $N$. asteroides NIOO and N2 I 6 did not correspond to those isolated from the other strains classified in the asteroides taxon is in apparent conflict with the results of Goodfellow (I97I). A re-examination of these organisms using conventional bacteriological tests confirmed their identity (M. Goodfellow, personal communication). The asteroides cluster is, however, a complex taxon and covers a wide range of variation; the lack of uniformity, even using good taxonomic characters, should therefore not be considered with alarm. The discrepancy raises the question of how much weight should be given to single chemotaxonomic characters when classifying bacteria, an issue which must be resolved in view of its far-reaching consequences for this and other characters of a precise chemical nature such as the mycolic acids (see Minnikin, Alshamaony \& Goodfellow, 1975). We believe, though, that the nocobactins can provide good characters in a chemical classification of the nocardiae.

P.V.P. thanks The Wellcome Trust for a research studentship. We thank Mrs J. Eagle for her laboratory assistance. We are indebted to Dr M. Goodfellow for his selection of cultures for this study and for his valuable comments on taxonomy.

\section{REFERENCES}

Goodfellow, M. (I971). Numerical taxonomy of some nocardioform bacteria. Journal of General Microbiology 69, 33-80.

Goodfellow, M. (1973). Characterisation of Mycobacterium, Nocardia, Corynebacterium and related taxa. Annales de la Société belge de médecine tropicale 53, 287-298.

Goodfellow, M., Lind, A., Mordarska, H., Pattyn, S. \& Tsukamura, M. (i974). A co-operative numerical analysis of cultures considered to belong to the 'rhodochrous' taxon. Journal of General Microbiology 85, 29I-302.

Jantzen, E. \& ANDREAS, H. (1961). Reaktion ungesättigter Fettsäuren mit Quecksilber (II)-acetat. Anwendung für präparative Trennungen, II. Chemische Berichte 94, 628-633.

KIRCHNER, J. G. ( 1967). Thin-layer chromatography. In Techniques of Organic Chemistry, vol. 1 2. Edited by A. Weissberger. New York: Interscience.

Minnikin, D. E., Alshamaony, L. \& Goodfellow, M. (1975). Differentiation of Mycobacterium, Nocardia and related taxa by thin-layer chromatographic analysis of whole-organism methanolysis. Journal of General Microbiology 88, 200-204.

Morrison, N. E. (1965). Circumvention of the mycobactin requirement of Mycobacterium paratuberculosis. Journal of Bacteriology 89, 762-767.

Patel, P. V. \& Ratledge, C. (I973). Isolation of lipid-soluble compounds that bind ferric ions from Nocardia species. Biochemical Society Transactions I, 886-887.

RatLedGe, C. \& Hall, M. J. (I97I). Influence of metal ions on the formation of mycobactin and salicylic acid in Mycobacterium smegmatis grown in static culture. Journal of Bacteriology 108, 314-319.

Ratledge, C. \& Marshall, B. J. (I972). Iron transport in Mycobacterium smegmatis: the role of mycobactin. Biochimica et biophysica acta 279, 58-74.

Ratledge, C. \& SNOW, G. A. (I974). Isolation and structure of nocobactin NA, a lipid-soluble ironbinding compound from Nocordia asteroides. Biochemical Journal r39, 407-413.

SNow, G. A. (1965). Isolation and structure of mycobactin T, a growth factor from Mycobacterium tuberculosis. Biochemical Journal 97, 166-175.

Snow, G. A. (1970). Mycobactins: iron-chelating growth factors from mycobacteria. Bacteriological Reviews 34, 99-1 25 .

Wheeler, W.C. \& Hanks, J. H. (1965). Utilization of external factors by intracellular microbes: Mycobacterium paratuberculosis and wood pigeon mycobacteria. Journal of Bacteriology 89, 889-896.

White, H. B. (1966). A complementary thin-layer and gas-liquid chromatographic procedure for fatty acid analysis. Journal of Chromatography 21, 2 I 3-222. 
White, A. J. \& SNOw, G. A. (1968). Methods for the separation and identification of mycobactins from various species of mycobacteria. Biochemical Journal 108, 593-597.

White, A. J. \& SNOw, G. A. (1969). Isolation of mycobactins from various mycobacteria. The properties of mycobactins S and H. Biochemical Journal IIr, 785-792.

Williams, S. J., Lacey, J., Serrano, J. A., de Serrano, A. A. \& Sharples, G. P. (1976). The micromorphology and fine structure of nocardioform organisms. In The Biology of the Nocardiae. Edited by M. Goodfellow, G. H. Brownell and J. A. Serrano. London: Academic Press (in the Press). 